\section{Gynäkologisch-}

Rundschau

\section{Therapieschema}

Perimenopause - zyklische

Sequenztherapie

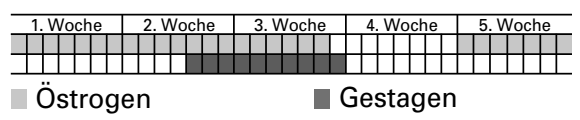

Peri- und Postmenopause sequentielle Therapie

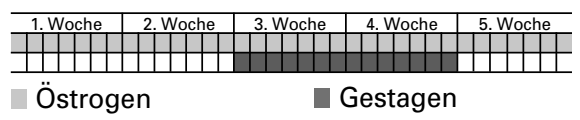

Postmenopause -

kontinuierliche Kombinationstherapie

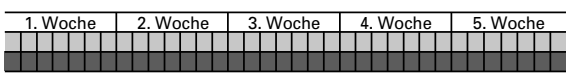

$$
\text { Östrogen Gestagen }
$$

Reine Östrogentherapie für hysterektomierte Frauen

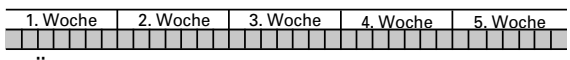

Östrogen

\title{
Leitfaden zur individuellen Hormonersatztherapie
}

Tabelle 1. Nebenwirkungen (nach Fischl F, 1998)

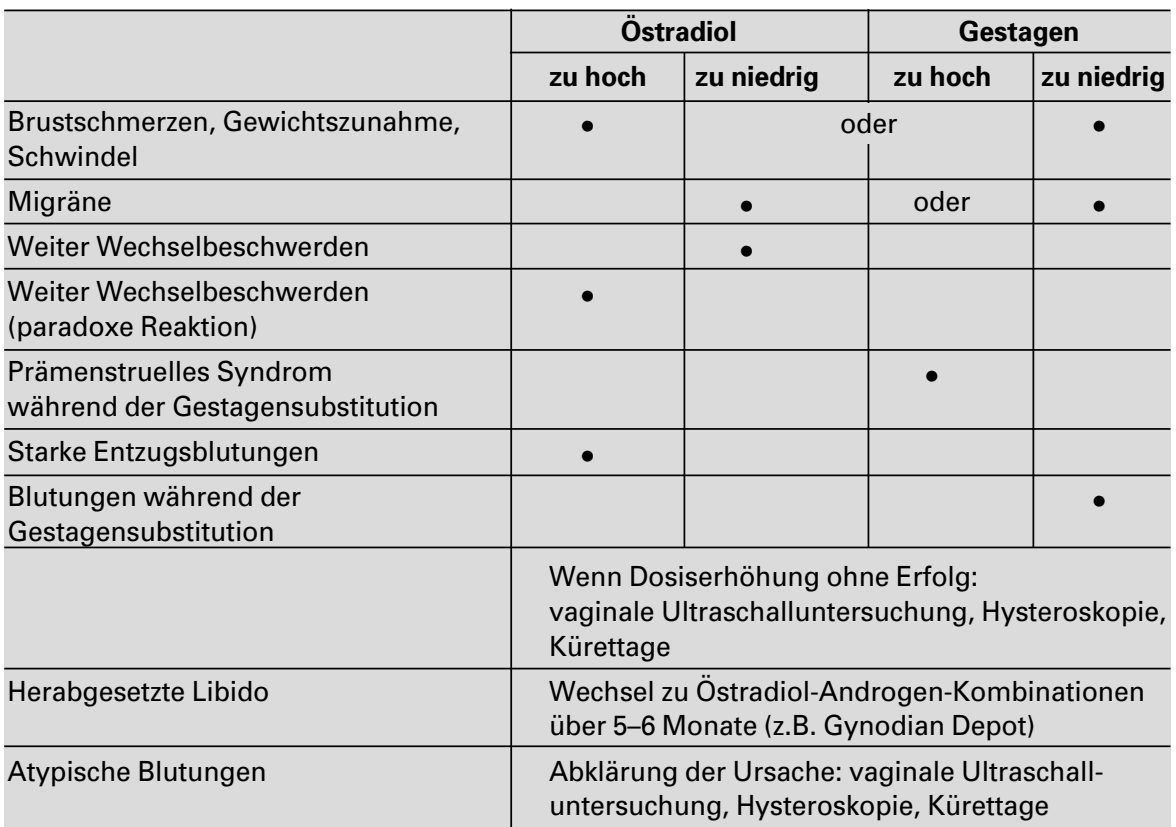

Bei zyklischer Gestagengabe ist eine Behandlungsdauer von 10 bis 14 Tagen erforderlich. Die dazu notwendigen Tagesdosen (11. Arbeitstreffen Zürcher Gesprächskreis) sind:
- $1 \mathrm{mg}$ Norethisteronazetat $\bullet 0,075 \mathrm{mg}$ Levonorgestrel

- 0,15 mg DL-Norgestrel

- 2 mg Chlormadinonazetat

- $1 \mathrm{mg}$ Cyproteronazetat

- $5 \mathrm{mg}$ Medroxyprogesteronazetat

- $5 \mathrm{mg}$ Medrogeston

Tabelle 2. Hormonersatztherapie mit Schering

\begin{tabular}{|c|c|c|c|}
\hline Präparat & Einheiten/Zyklus & Östrogengehalt & Gestagengehalt \\
\hline $\begin{array}{l}\text { Oral } \\
\text { Kombinationspräparate } \\
\text { Climen-Dragées } \\
\text { Cyclacur-Dragées }\end{array}$ & $\begin{array}{l}21 \\
21\end{array}$ & $\begin{array}{l}11 \times 2 \text { mg Östradiolvalerat } \\
10 \times 2 \text { mg Östradiolvalerat } \\
11 \times 2 \text { mg Östradiolvalerat } \\
10 \times 2 \text { mg Östradiolvalerat }\end{array}$ & $\begin{array}{l}1 \mathrm{mg} \text { Cyproteronazetat } \\
0,5 \mathrm{mg} \text { Norgestrel }\end{array}$ \\
\hline $\begin{array}{l}\text { Östrogenpräparate } \\
\text { Progynova-Dragées } \\
\text { Progynova-mite-Dragées }\end{array}$ & & $\begin{array}{l}2 \mathrm{mg} \text { Estradiolvalerat } \\
1 \mathrm{mg} \text { Estradiolvalerat }\end{array}$ & \\
\hline $\begin{array}{l}\text { Gestagenpräparate } \\
\text { Primolut-Nor-Tabletten }\end{array}$ & & & $5 \mathrm{mg}$ Norethisteronazetat \\
\hline $\begin{array}{l}\text { Transdermal } \\
\text { Climara } 50 \mu \mathrm{g} / 24 \mathrm{~h} \text { Depot-Pflaster } \\
\text { Climara } 100 \mu \mathrm{g} / 24 \text { h Depot-Pflaster }\end{array}$ & $\begin{array}{l}28 \text { (Matrix, 1mal wöchentlich) } \\
28 \text { (Matrix, 1mal wöchentlich) }\end{array}$ & $\begin{array}{l}3,9 \mathrm{mg} \text { Östradiol } \\
7,8 \mathrm{mg} \text { Östradiol }\end{array}$ & \\
\hline $\begin{array}{l}\text { Injizierbar } \\
\text { Gynodian-Depot-Spritzampullen }\end{array}$ & 1 & $\begin{array}{r}4 \mathrm{mg} \text { Östradiolvalerat } \\
200 \mathrm{mg} \text { Pas }\end{array}$ & ntat (DHEA) \\
\hline
\end{tabular}

\section{KARGER}

Fax+4161306 1234 E-Mail karger@karger.ch www.karger.com
(C) 1998 S. Karger AG, Basel
Weitere Informationen:

Schering Wien GmbH, Frau Mag. Haslinger

Scheringgasse 2, A-1140 Wien (Österreich)

Tel. +431970 37 0, Fax +431970 37161 